\title{
Oligodendroglia Development in Cell Culture as Monitored with a Monoclonal Antibody
}

\author{
Janet M. Collins and Nicholas W. Seeds \\ Department of Biochemistry, Biophysics, and Genetics, University of Colorado Health Sciences Center, Denver, \\ Colorado 80262
}

\begin{abstract}
A new marker for young oligodendrocytes has been identified by a monoclonal antibody (mOg-1, IgM isotype) prepared from cerebellar plasma membrane stimulated mouse lymphocytes. $\mathrm{mOg}-1$ reactive cells in the mouse cerebellum first appear at day 19 of gestation. Future white matter layers of fixed sections of neonatal rat cerebellum were labeled with $\mathrm{mOg}-1$. Although $\mathrm{EM}$ analysis has shown cell-surface binding by presumptive oligodendroglia in neonatal cerebellum, the antibody does not bind to compact myelin. In cell cultures prepared from 6-d-old mice, $1.1 \%$ of the cells bound $\mathrm{mOg}-1$ after $3 \mathrm{~d}$ in culture, but up to $5 \%$ of the cells bound $\mathrm{mOg}-1$ after 2 weeks in culture. Of these same $\mathrm{Og}-1$-positive cells, $69 \%$ bound anti-galactocerebroside and $65 \%$ bound anti-myelin basic protein. After a week in culture Og-1-positive cells often produced lamellar sheets extending a millimeter over the polylysine substratum in the absence of normal myelin formation. $\mathrm{mOg}-1$ recognizes a cell-surface determinant distinct from well-characterized oligodendroglial molecules (galactocerebroside, sulfatide and myelin basic protein) that is expressed early in oligodendrocyte development. The antibody has been used to follow the maturation of oligodendrocytes in cultures of both normal and jimpy mouse cerebellum.
\end{abstract}

The nervous system is a complex network derived from multiple associations between different cell types. The limited number of distinct cell types and the availability of neurological mutants with defective cerebellar histogenesis make the mouse cerebellum an attractive model for studying cell-cell interactions. The development of antibodies toward neural cell-surface molecules could be instrumental in establishing the role of specific determinants in histogenesis. We have used the hybridoma technology of Kohler and Milstein $(1975,1976)$ to prepare monoclonal antibodies that might be employed to identify neural cell types in culture, analyze cell lineage relationships, and investigate cell interactions in reaggregate cultures. Sheep cerebellar plasma membranes were used to immunize $B A L B / c$ mice. The resulting hybridomas were tested for production of monoclonal antibodies cross-reactive with cerebellar cultures prepared from mice.

In this report, we describe a monoclonal antibody (mOg-1) reactive with the surface of young oligodendrocytes, prior to the

\footnotetext{
Received Dec. 19, 1985; revised Mar. 4, 1986; accepted Mar. 4, 1986.

We woula like to thank Dr. Robert Lasher for his helpful discussions and $\mathbf{S}$. Haffke for her expert assistance. We thank Drs. Dahl, DeVellis, Evans, Habig, Quarles, Ranscht, and Rapport for their generous gift of antisera and tetanus toxin used in these studies. Some of these studies were submitted in partial fulfillment of the requirements for the Doctor of Philosophy degree from the University of Colorado (1983). This work was supported in part by USPHS Grants NS-09818 and T32-GM-07342.

Correspondence should be addressed to N. W. Seeds, Ph.D., Department of Biochemistry, Biophysics, and Genetics, University of Colorado Health Sciences Center, 420u E. 9th Avenue, B-121, Denver, CO 80262.

Copyright (C) 1986 Society for Neuroscience 0270-6474/86/092635-09\$02.00/0
}

appearance of galactocerebroside on these cultured cells. This antibody has been used to monitor oligodendrocyte maturation in cerebellar cultures. A preliminary report of these studies has previously appeared (Seeds and Collins, 1983).

\section{Materials and Methods}

\section{Animals}

All mice were obtained from Jackson Laboratories, (Bar Harbor, ME) and maintained as a breeding colony. C57B1/6 and jimpy mice were used for cell culture, while BALB/c mice were used for immunizations. Sprague-Dawley rats were a gift from Dr. Robert Lasher. Lamb brains were purchased from Colorado Lamb Co. (Denver, $\mathrm{CO}$ ).

\section{Cell suspensions and cultures}

The cerebellum was removed from fetal or postnatal mice of various ages and dispersed into a single-cell suspension, as described previously (Krystosek and Seeds, 1981). Diced tissue was dissociated in a solution of $0.25 \%$ trypsin (hog pancreas, ICN Pharmaceuticals) and $0.6 \mathrm{mg} \%$ deoxyribonuclease (DNase 1, bovine pancreas, Nutritional Biochemicals) in saline $1\left(0.138 \mathrm{M} \mathrm{NaCl}, 5.4 \mathrm{mM} \mathrm{KCl}, 1.1 \mathrm{mM} \mathrm{Na}_{2} \mathrm{HPO}_{4}, 1.1\right.$ mM $\mathrm{KH}_{2} \mathrm{PO}_{4}$ ) containing $0.4 \%$ glucose and $0.01 \% \mathrm{CaCl}_{2}$. The suspension was incubated for $12 \mathrm{~min}$ at $37^{\circ} \mathrm{C}$, dispersed by gentle pipetting in basal Eagle's medium (BEM) with $10 \%$ fetal calf serum (FCS), and passed through a $200 \mu \mathrm{m}$ Nylon screen. Surface cultures were prepared from the dissociated cells by pipetting them onto $18 \mathrm{~mm}$ glass coverslips previously coated with poly-(D-lysine) (Yavin and Yavin, 1977). The cultures were maintained at $37^{\circ} \mathrm{C}$ in a $5 \% \mathrm{CO}_{2}: 95 \%$ air incubator. Schwann cell cultures were initiated by dissecting the root portions of dorsal root ganglia from $2 \mathrm{~d}$ postnatal mice and preparing cell suspensions as described by Ransom et al. (1977). Briefly, the tissue was treated with $0.25 \%$ collagenase at $37^{\circ} \mathrm{C}$ for $5 \mathrm{~min}$, triturated with Sigma Cote-d Pasteur pipettes in $0.5 \mathrm{ml}$ serum-free culture media containing $10 \mu \mathrm{g}$ DNase, and washed and pipetted on coverslips as above. Clonal cell lines, including the methylcholanthrene-induced rat astrocytoma $\mathrm{C}_{6}$ (Benda et al., 1968) and mouse oligodendroglioma $G_{26}$ (Zimmerman and Maier, 1948), as well as an ethylnitrosourea-induced mouse schwannoma TRM6B (Fields et al., 1975), were cultured on coverslips in Dulbecco's modification of Eagle's medium (DMEM) with 5-10\% fetal calf serum in an atmosphere of $10 \% \mathrm{CO}_{2}: 90 \%$ air.

\section{Monoclonal antibody production}

$\mathrm{BALB} / \mathrm{c}$ mice were immunized with cerebellar plasma membranes prepared as described by Stuhlfauth and Seeds (1983) from bovine cerebellum. We used 100-500 $\mu \mathrm{g}$ protein, determined by the method of Lowry et al. (1951), for each injection. Initially, 0.2-0.4 ml of a 1:1 suspension with complete Freund's adjuvant was injected subcutaneously. Subsequently, mice were injected intraperitoneally minus adjuvant at 2 week intervals ( $3-4$ times). Spleen cells from one mouse were fused $4 \mathrm{~d}$ after the last injection with hypoxanthine/aminopterin/thymidine-sensitive myeloma cells P3-NS-1/-Ag 4-1 (Kohler et al., 1976) at a ratio of $3: 1$ in the presence of $40 \%$ Merck PEG 4000 containing $15 \%$ dimethylsulfoxide by the procedure of Galfre et al. (1977). The fused cells were distributed into five 24-well Costar dishes preconditioned with $5 \times 10^{4}$ peritoneal macrophages/well in complete HAT medium. The cultures were fed every 3-4 d. 
Approximately 2 weeks after fusion, aliquots of media were removed for testing from those wells that showed substantial growth and concentrated 10 -fold by precipitating in $45 \%$ saturated ammonium sulfate. Dialyzed supernatants were then tested by immunofluorescence with surface cultures. Antibody-producing hybridoma cells were cloned twice by the limiting dilution method of Oi and Herzenberg (1980).

\section{Immunofluorescence}

Indirect immunofluorescence labeling of surface cultures was used for testing immunized mouse sera and hybridoma supernatant samples, and for analysis of cell-type specificity of monoclonal antibodies. In addition to $\mathrm{mOg}-1$, the following cell-type-specific antibodies were used: a rabbit antiserum raised against galactocerebroside ( $\mathrm{rGalC}$, \#68R-1594) (Joffe and Rapport, 1963), a mouse monoclonal to galactocerebroside (mGalC) (Ranscht et al., 1982), a rabbit anti-glycerol-3-phosphate dehydrogenase (rG3PDH) (Leveille et al., 1980), a rabbit anti-glial fibrillary acidic protein (rGFAP) (Dahl and Bignami, 1973), a rabbit antivimentin (gift of Dr. R. Evans), a mouse monoclonal (IgG) anti-myelin basic protein (mMBP) (Hybritech, Inc., San Diego, CA), a rabbit antiserum raised against neonatal mouse cerebellum (r Cbl-l) (Seeds, 1975), and tetanus toxin and rabbit anti-tetanus toxin (Yavin et al., 1981). Cultured cells on coverslips were incubated with $30 \mu \mathrm{l}$ of diluted antibody, rinsed 5 times with saline 1 containing $10^{-4} \mathrm{M} \mathrm{CaCl}_{2}$ and $10^{-3} \mathrm{M}$ $\mathrm{MgCl}_{2}$, fixed for $5 \mathrm{~min}$ with $4 \%$ paraformaldehyde, washed, and incubated with fluorescein (FITC) or tetramethyl rhodamine (TRITC)-conjugated second antibodies.

For double indirect immunofluorescence with mOg-1 and rGalC, coverslips were incubated simultaneously with the 2 antibodies, washed, fixed, and incubated with a mixture of FITC-goat anti-mouse Ig (GAM) (Meloy Laboratories, Springfield, VA) and TRITC-goat anti-rabbit Ig (GAR) (Cappel Laboratories, Malvern, PA).

A similar procedure was used for mouse GalC and $\mathrm{mOg}-1$; however, TRITC-GAM $\mu$-chain (affinity-purified, TAGO, Inc., Burlingame, CA) and FITC-GAM $\gamma$-chain (Cappell Laboratories, Malvern, PA) were used. For studies using rG3PDH, r-vimentin, or rGFAP, coverslips were incubated with $\mathrm{mOg}-1$, washed, fixed, and then treated with methanol for $5 \mathrm{~min}$ at $-20^{\circ} \mathrm{C}$ to permeabilize the cell membrane. The cultures were next incubated with rG3PDH, r-vimentin, or rGFAP, and finally with a mixture containing FITC-GAM and TRITC-GAR. Double labeling with mOg-1 and mMBP on cerebellar cultures was done in a sequential fashion. Live cells were incubated with $\mathrm{mOg}-1$, washed, fixed with $4 \%$ paraformaldehyde for $5 \mathrm{~min}$, and permeabilized with $0.05 \%$ Triton X-100 for $2 \mathrm{~min}$, incubated with $\mathrm{mMBP}$, washed, and incubated with the FITC-GAM $\gamma$-chain specific and TRITC-GAM $\mu$-chain specific. Finally, double labeling with $\mathrm{mOg}-1$ and tetanus toxin (the generous gift of Drs. W. Habig and M. Hardegee) was performed by incubating the coverslip first with a mixture of the 2 markers, then with rabbit anti-tetanus toxin, fixing, incubating with TRITC-goat anti-rabbit Ig (GAR) and with FITC-GAM. Coverslips were mounted facedown in Gelvatol (Monsanto, St. Louis, MO) and examined with a Zeiss epifluorescence microscope.

\section{Immunostaining and electron microscopy of fixed sections}

Rats of various ages were sedated with $15 \%$ chloral hydrate, perfused through the left ventricle with cold $5 \%$ paraformaldehyde in $0.15 \mathrm{M}$ Sorenson's $\mathrm{PO}_{4}$ buffer containing $0.08 \mathrm{~m}$ sucrose at $\mathrm{pH}$ 7.7. Brains were removed, dissected, and fixed further for $3.5 \mathrm{hr}$. Vibratome sections, $30 \mu \mathrm{m}$, were stained in a 24 -well dish with $\mathrm{mOg}-1$ at $4^{\circ} \mathrm{C}$ overnight, then incubated with $1 \mathrm{ml}$ monospecific rabbit (IgG) anti-mouse IgM for $60 \mathrm{~min}$, and finally labeled with $1 \mathrm{ml}$ HRP-GAR IgG (TAGO, Burlingame, CA). Peroxidase labeling was achieved by the addition of $0.5 \mathrm{ml}$ of $0.05 \% \mathrm{DAB}-\mathrm{HCl}$ for $10 \mathrm{~min}$, followed by $5.5 \mu \mathrm{l}$ of $0.3 \%$ solution of $\mathrm{H}_{2} \mathrm{O}_{2}$ for 10 min.

Sections were prepared for electron microscopy by incubation with $1 \% \mathrm{OsO}_{4}$, dehydration with $50,70,95$, and $100 \%$ ethanol, 2-hydroxypropylmethacrylate, and lastly Epon 50:50 mix with catalyst. The sections were mounted between Aclar fluorocarbon film, polymerized, and attached with epoxy glue to an Epon block. They were then thin-sectioned for examination with a Philips 300 EM.

\section{Autoradiography}

Surface cultures on coverslips were exposed to ${ }^{3} \mathrm{H}$-thymidine $(2 \mu \mathrm{Ci} /$ $\mathrm{ml}$ ) for $72 \mathrm{hr}$, washed, labeled by indirect immunofluorescence and airdried. The coverslips were mounted faceup on slides and coated with
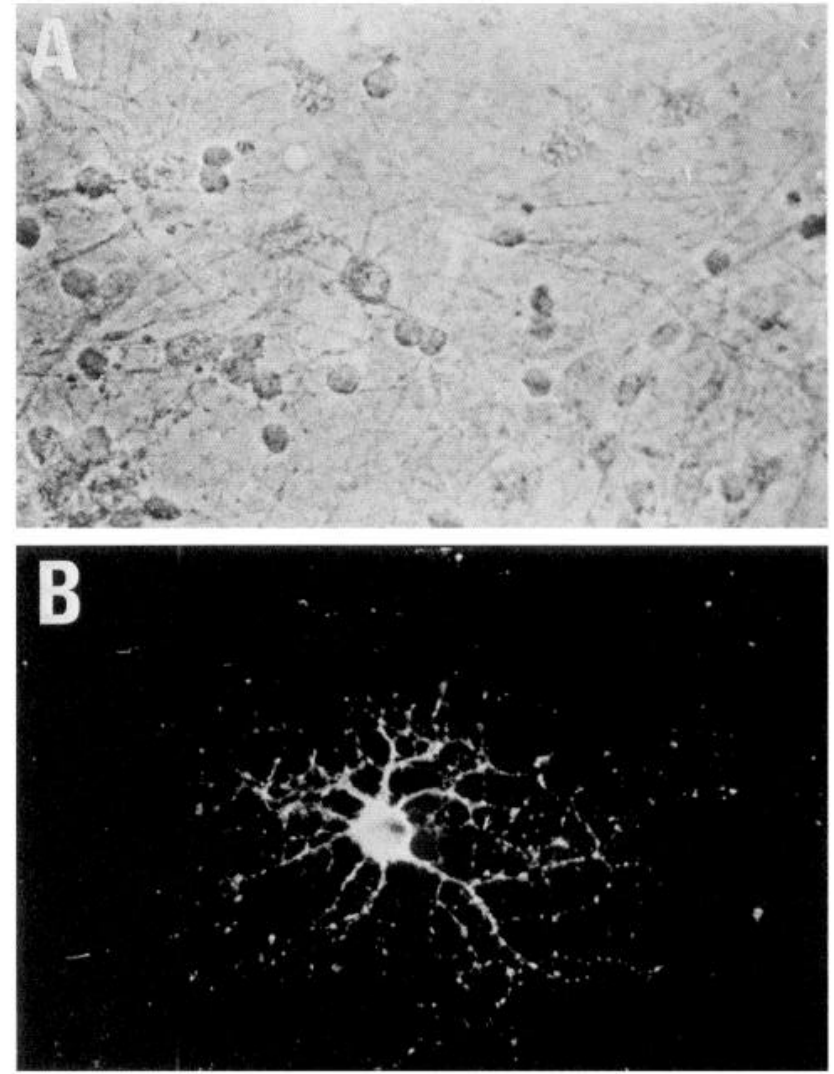

Figure 1. Binding of mouse monoclonal antibody mOg-1 to dissociated cerebellar cells from 6 -d-old mice. Concentrated culture media from mouse hybridoma $52 \mathrm{C} 3$ was incubated with $4 \mathrm{~d}$ cerebellar cultures and visualized with FITC-goat anti-mouse immunoglobulin. Only a single cell in this field possesses the Og-1 antigen.

Kodak NTB2 emulsion. After 3-6 d at $4^{\circ} \mathrm{C}$, they were developed with Kodak Dektol, mounted, and examined with phase and fluorescence optics.

\section{Complement-dependent cytotoxicity}

Monolayer cultures of cerebellar cells from 6- to 8-d-old C57BL/6 mice were maintained in vitro for $1 \mathrm{~d}$. Some of the coverslips were then removed, washed with BEM without serum, and incubated with monoclonal antibody and guinea pig complement (diluted 1:6) for $20 \mathrm{~min}$ at $37^{\circ} \mathrm{C}$ in a $5 \% \mathrm{CO}_{2}: 95 \%$ air incubator. All dilutions were made in BEM. The reaction was terminated by 2 gentle rinses with BEM containing $10 \%$ fetal calf serum. Cultures were immediately processed for immunocytological analysis or maintained in sterile conditions in BEM with $10 \%$ fetal calf serum.

\section{Results Cell-type specificity of $\mathrm{mOg}-1$}

Supernatants from mOg-1-producing clones were used to label cerebellar cultures of $6-8 \mathrm{~d}$ postnatal C57BL/ 6 mice grown for $4 \mathrm{~d}$ in vitro. Only cells with an oligodendrocyte-like morphology were stained (Fig. 1), and these constituted $1.1 \%$ of the total viable cells. This specificity for oligodendrocytes was confirmed by double-labeling studies that used $\mathrm{mOg}-1$ with other antibodies specific to various neural cell types. Cells binding mOg-1 did not react with tetanus toxin (a neuronal marker), anti-Cbl1 (a neuronal marker), or anti-GFAP (an astrocyte marker) (Fig. 2). The $\mathrm{mOg}-1$-reactive cells did not bind rabbit anti-vimentin, a marker for mesenchymal intermediate filaments (Fig. 3). However, subsets of mOg-1-positive cells did bind $\mathrm{mGalC}$, rG3PDH, and $\mathrm{mMBP}$ (Fig. 4). GalC, the major glycolipid in myelin (Nor- 

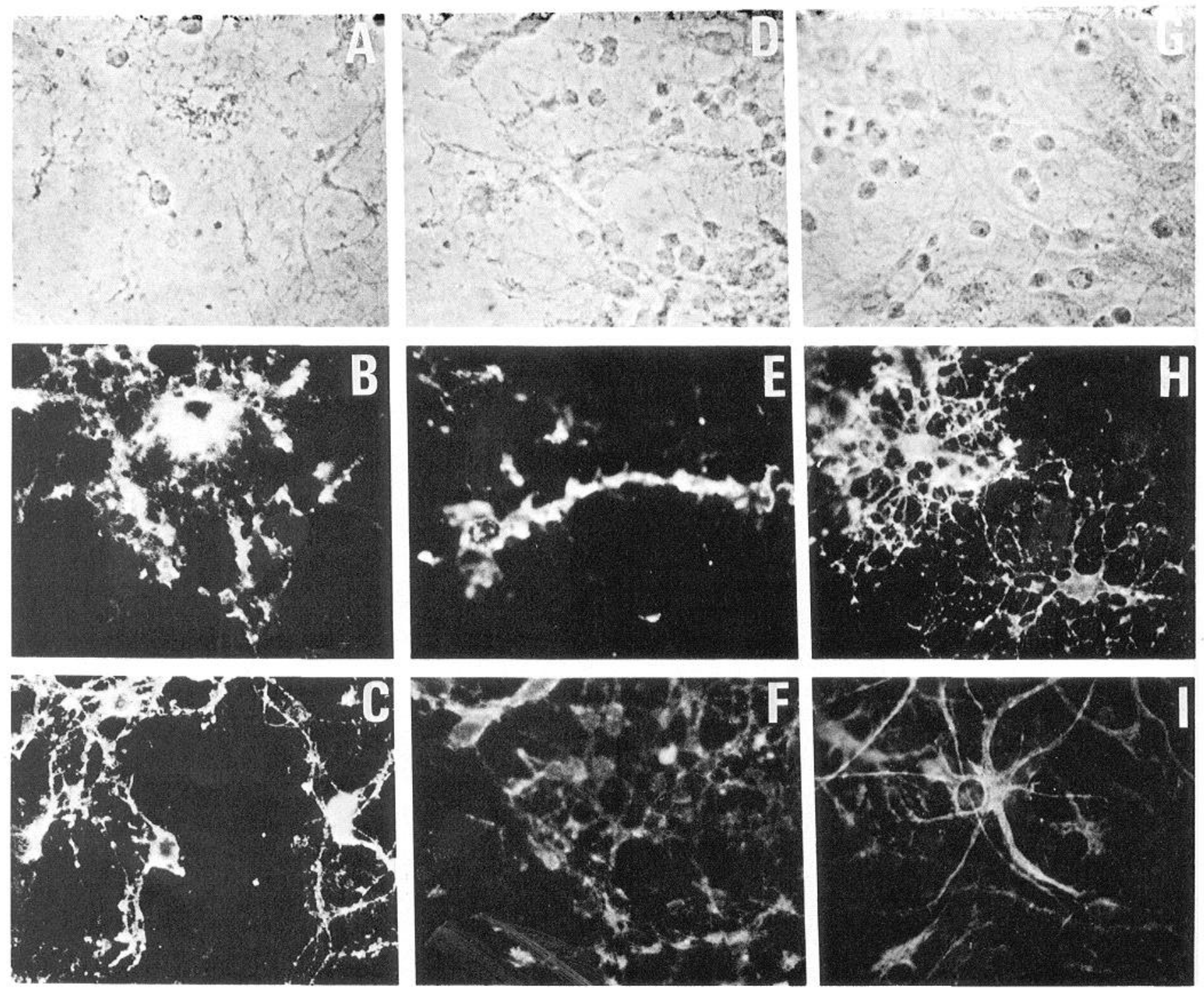

Figure 2. Double-labeling with $\mathrm{mOg}-1$ antibody and specific neuronal and astrocyte markers. Dissociated cerebellar cells $(A)$ were incubated with tetanus toxin, rabbit anti-tetanus toxin $(C)$ and mOg-1 $(B)$. Another neuronal marker anti-Cbl-1 $(F)$ was used with mOg-1 $(E)$ to distinguish cerebellar cell populations $(D)$. The astrocyte specific anti-GFAP $(I)$ was added to cells $(G)$ labeled with mOg-1 $(H)$. Fluorescent conjugates were used to visualize these bound antibodies, as described in Materials and Methods. The mOg-1 antibody reacts with a cell population distinct from these neuronal and astrocytic cells.

ton and Autilio, 1966), has been shown to be expressed only by oligodendrocytes in a variety of rat (Raff et al., 1978), human (Kennedy et al., 1980), and bovine (Lisak et al., 1981) CNS cultures; however, not all mOg-1 cells bind anti-GalC (Fig. 4C). G3PDH has also been used as a oligodendrocyte marker (Leveille et al., 1980). Although G3PDH enzyme appears to be localized primarily in oligodendrocytes, it is also present in lesser amounts in astroglial cell cultures(McCarthy and DeVellis, 1980). Myelin basic protein (MBP), an important component of myelin, can be detected in oligodendrocytes prior to myelination (Sternberger et al., 1978). In dissociated brain cell cultures, where myelination does not take place, oligodendrocytes are still able to express MBP (Bologa-Sandru et al., 1981). The MBP reactivity is confined to the more central structures of the Og-1positive cells (Fig. 4, E, F). In additional studies, cells binding rabbit antibody to myelin associated glycoprotein also bound mOg-1 (results not shown).

Schwann cells, the PNS equivalent of oligodendrocytes, prepared from dorsal root ganglia, were incubated with mOg-1. Labeled cells exhibiting the bipolar spindle shape characteristic of Schwann cells are shown in Figure 5. Some dependence of mOg-1 labeling on length of time in culture was noted. After 4 $\mathrm{d}$ in culture this marker is apparently lost. Dorsal root ganglia neurons were negative at all times tested.

Clonal tumor cell lines of presumed glial and Schwann cell origin - the rat astrocytoma $\mathrm{C} 6$, the mouse oligodendroglioma G26, and schwannoma TRM6B - were also tested for immunolabeling with $\mathrm{mOg}-1$. Even though we included $\mathrm{G} 26$, a presumptive oligodendroglioma that has been shown to synthesize sulfatide, a myelin component (Seeds and Marks, 1979), all 3 cell lines were negative for mOg-1 binding, when tested shortly after initiation or at confluency. If $\mathrm{mOg}-1$ antigen is involved in the differentiated functions of myelinating cells, it is apparently lost in establishment of these cell continuous lines.

\section{Localization of $\mathrm{mOg}-1$ staining in brain sections}

White matter was very heavily labeled at day 8 (Fig. $6 \mathrm{~A}$ ), and occasional cells subadjacent to the internal granular layer were labeled at day 3 (not shown). White matter and structures of the internal granular layer were labeled in fixed sections of the 
adult rat cerebellum (not shown). White matter portions of other brain areas were also labeled with $\mathrm{mOg}-1$. Antibody to $\mathrm{GalC}$ showed a similar labeling of cerebellar sections. Cells deep in the granule layer and white matter showed surface labeling with mOg-1 at the EM level (Fig. $6 B$ ). Although morphology of these cells is inconclusive, their position, nuclear morphology, and electron opacity are suggestive of oligodendroglial cells. Other cells, identified as mature oligodendrocytes by the criteria of Privat (1975) and Skoff et al. (1976), were not stained with mOg1. Neither were several examples of compact myelin. Similar staining distribution has been observed with frozen sections of mouse cerebellum.

\section{Developmental studies}

Cell suspensions were prepared from the cerebellum of fetal and postnatal mice of various ages. Binding of $\mathrm{mOg}-1$ to 1 aliquot of the cells was determined after $4 \mathrm{hr}$ by immunofluorescence. A second portion of cells was placed in culture and immunolabeled $24 \mathrm{hr}$ later, when a distinctive morphology could be seen in cultures. The earliest time positive cells were seen in suspensions was fetal day 19 , or in cultures prepared from an $18 \mathrm{~d}$ fetal mouse and maintained $1 \mathrm{~d}$ in culture. Thus, we conclude that Og-1 m first makes its appearance at fetal day 19. Cultures prepared from younger animals and maintained for longer periods of culture confirmed this finding. For example, cultures prepared from $15 \mathrm{~d}$ fetal mice contained $\mathrm{Og}$-1-positive cells after 3-5 $\mathrm{d}$ in culture, suggesting that in terms of Og-1 expression, maturation in culture parallels that seen in vivo.

In cell cultures prepared from 6 -d-old mice, $1.1 \%$ of the cells bound $\mathrm{mOg}-1$ after $3 \mathrm{~d}$ in culture. After 2 weeks in culture, up to $5 \%$ of the cells bound $\mathrm{mOg}-1$. This culture period was typified by a decrease in small uni-and bipolar cells and by proliferation of astrocytes. Where these percentages are relative, the actual numbers of Og-1-positive cells were apparently increasing as judged by Og-1-positive cells/field. Though much of the increase may derive from maturation of $\mathrm{Og}$-1-negative precursors, a portion may be related to proliferation of these precursor cells or possibly the Og-1-positive cells themselves. Cultures incubated for $72 \mathrm{hr}$ with ${ }^{3} \mathrm{H}$-thymidine and immunolabeled with $\mathrm{mOg}-1$ and FITC-GAM contained Og-1-positive cells that had incorporated thymidine (Fig. 7).

Since monoclonal antibody $\mathrm{mOg}-1$ was found to be complement-fixing and to be IgM by Ouchterlony analysis using classspecific anti-mouse immunoglobulins, this problem was also investigated using complement-mediated lysis of $\mathrm{Og}$-1-positive cells in culture. Cerebellar cultures prepared from $6 \mathrm{~d}$ postnatal mice were treated after $1 \mathrm{~d}$ in culture with $\mathrm{mOg}-1$ and guinea pig complement. The complement control indicated that at the dilution used (1:6) the complement alone was not cytotoxic. However, when tested $3 \mathrm{hr}$ after treatment, no intact cells labeled with $\mathrm{mOg}-1$ could be found. After several days, Og-1-positive cells were again observed in the culture. This phenomenon was quantified. Coverslips were withdrawn from culture at $2 \mathrm{~d}$ intervals and the relative number of $\mathrm{Og}-1$-positive cells determined (Fig. 8). The percentage of Og-1-positive cells in the control cultures rises steadily for the first $4 \mathrm{~d}$ after treatment. An apparent decrease was seen at day 6, but this may be due to the very fast proliferation of astrocytes during this period, since the value is calculated as the percentage of total cells. An increase was likewise seen in Og-1-positive cells $2 \mathrm{~d}$ after complement lysis in the presence or absence of $10^{-5} \mathrm{M}$ cytosine arabinoside, indicating that a nondividing precursor for $\mathrm{Og}-1$ was present in the culture at the time of complement-dependent lysis. However, the increase by $4 \mathrm{~d}$ suggests that some division of Og-1 precursor cells may be required for maximal expression of Og-1 in these cerebellar cultures. These findings confirm the hypothesis that precursors of Og-1-positive cells exist in the cultures at day 1 and express the $\mathrm{Og}-1$ antigen at later times.
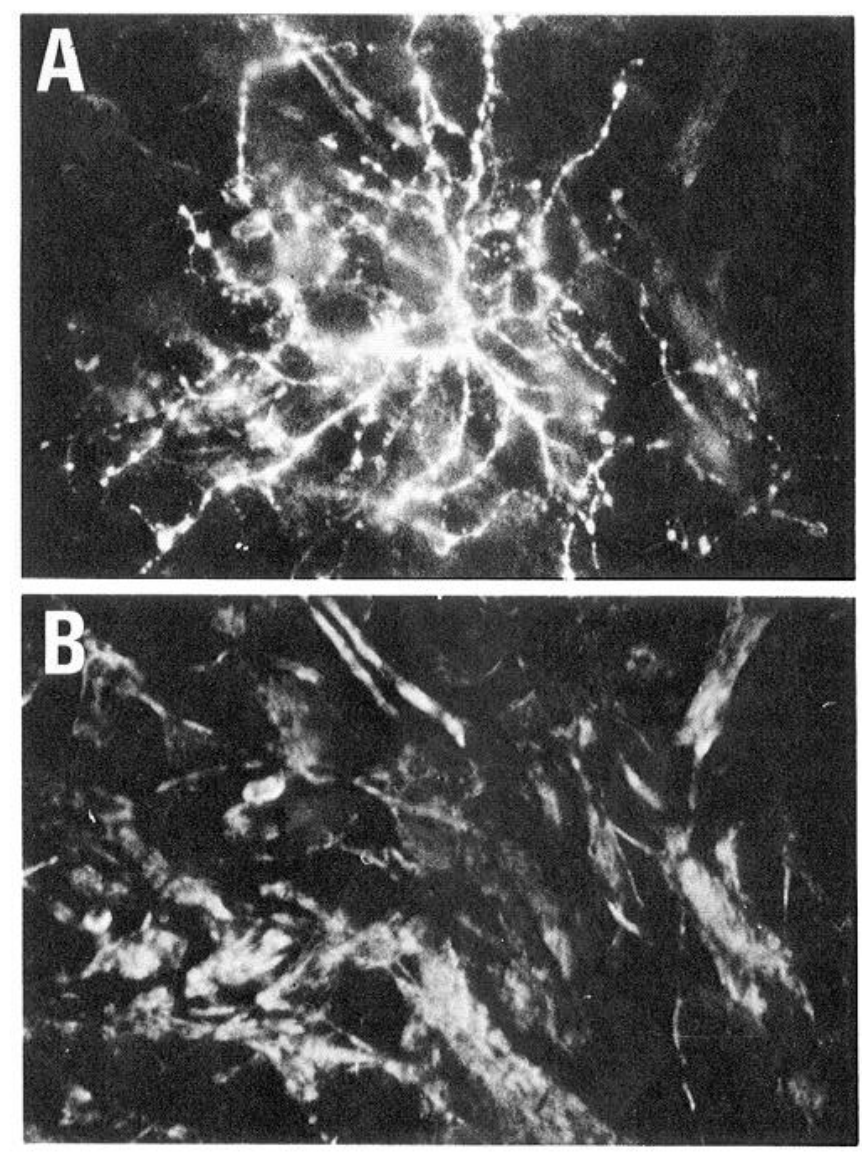

Figure 3. Double labeling with $\mathrm{mOg}-1$ and vimentin. After $4 \mathrm{~d}$ in culture, dissociated cerebellar cells were incubated with mOg-1 $(A)$, fixed, and incubated with rabbit anti-vimentin $(B)$ and fluorescent conjugates as described in Materials and Methods. Vimentin filaments are characteristic of mesenchymal cells and are not present in oligodendrocytes.

Since Og-1-positive cells appear capable of maturing in culture, will they all acquire additional oligodendrocyte markers as well? As shown in Table 1, the percentage of Og-1-positive cells double-labeled with oligodendrocyte markers increased with time in culture. After $14 \mathrm{~d}$ in culture, $69 \%$ of the oligodendrocyte cells bound $\mathrm{mGalC}$ and $65 \%$ bound mMBP. If the presence of these markers is considered indicative of maturation, the remainder of the Og-1-positive cells may not fully mature in vitro. However, $100 \%$ of the GalC and MBP-labeled cells were Og1-positive.

A procedure has been reported by McCarthy and DeVellis (1980) for obtaining relatively pure populations of oligodendroglial cells from mixed cultures of rat cerebral tissue. We have applied this technique to the mouse, and the purified cultures contained more than $95 \%$ oligodendrocytes as judged by morphological criteria. The contaminating cells were astrocytes. All of the oligodendrocytes bound both $\mathrm{mOg}-1$ and rGalC (i.e., $100 \%$ of the $\mathrm{Og}-1$-positive cells bound $\mathrm{rGalC}$ ). This procedure, however, may well select for only the more mature oligodendroglial cells.

In an attempt to enhance oligodendroglial differentiation, cells from $8 \mathrm{~d}$ cerebellum maintained in culture for $3 \mathrm{~d}$ in BEM plus $5 \%$ FCS were switched to a serum-free medium, N2 (Bottenstein and Sato, 1979), for $5 \mathrm{~d}$. Although the percentage of mOg-1positive cells increased from 9 to $20 \%$ of the cell population on day 8 , the total number of $\mathrm{mOg}$-1-positive cells per coverslip was only $74 \%$ of that number in serum-grown cultures after 8 d. This finding suggests that under these conditions $\mathrm{mOg}-1$ - 

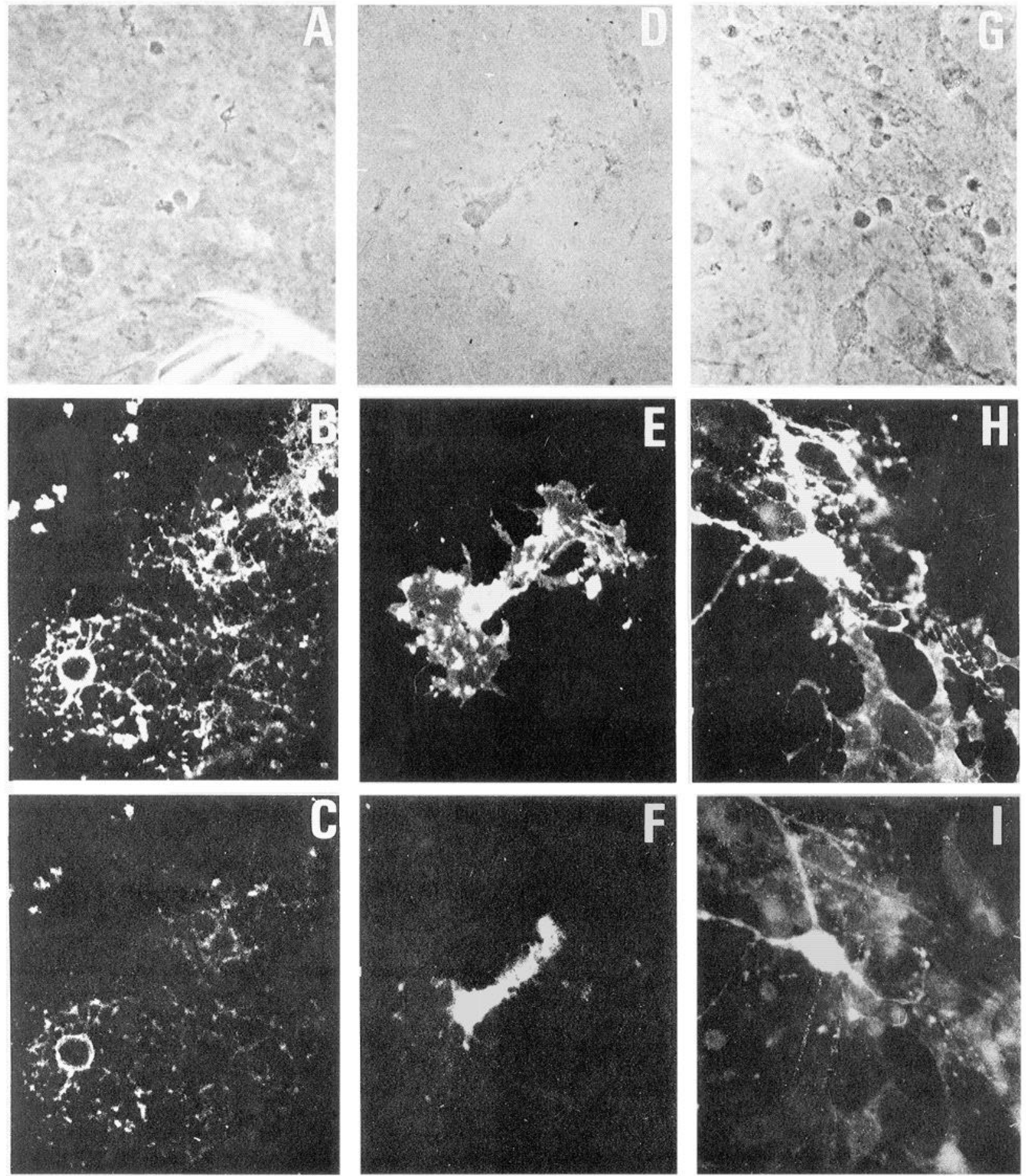

Figure 4. Double labeling of mOg-1 and oligodendroglial markers. Dissociated cerebellar cells $(A, D, G)$ were incubated with mOg-1 $(B, E, H)$ and anti-GalC $(C)$, anti-MBP $(F)$, and anti-glycerol phosphate dehydrogenase $(I)$ as described in Materials and Methods. Not all mOg-1-positive cells are positive for GalC binding (see $B$ and $C$ ).

positive cells were more likely to survive the switch to serumfree conditions than were some other cell types, but additional cerebellar cells were not directed toward oligodendrocyte differentiation. However, if the cells were switched to $\mathrm{N} 2$ after only $1 \mathrm{~d}$ of culture, similar cell numbers and a 2-fold increase in the percent mOg-1-positive cells compared to serum grown cultures were found at day 4; similar to the observation of Raff et al., (1983) with optic nerve cultures.
Some forms of oligodendroglial cells can produce "veil-like" membranous structures in culture (Sommer and Schachner, 1981; Szuchet and Stefansson, 1980). After a week in culture, Og-1positive cells often produced lamellar sheets extending for millimeters over the polylysine substratum (Fig. 9). These cells most likely correlate with the "active oligodendroglial" cells described by Tennekoon et al. (1980), which, by other criteria, are classified as probable oligodendroblasts. 

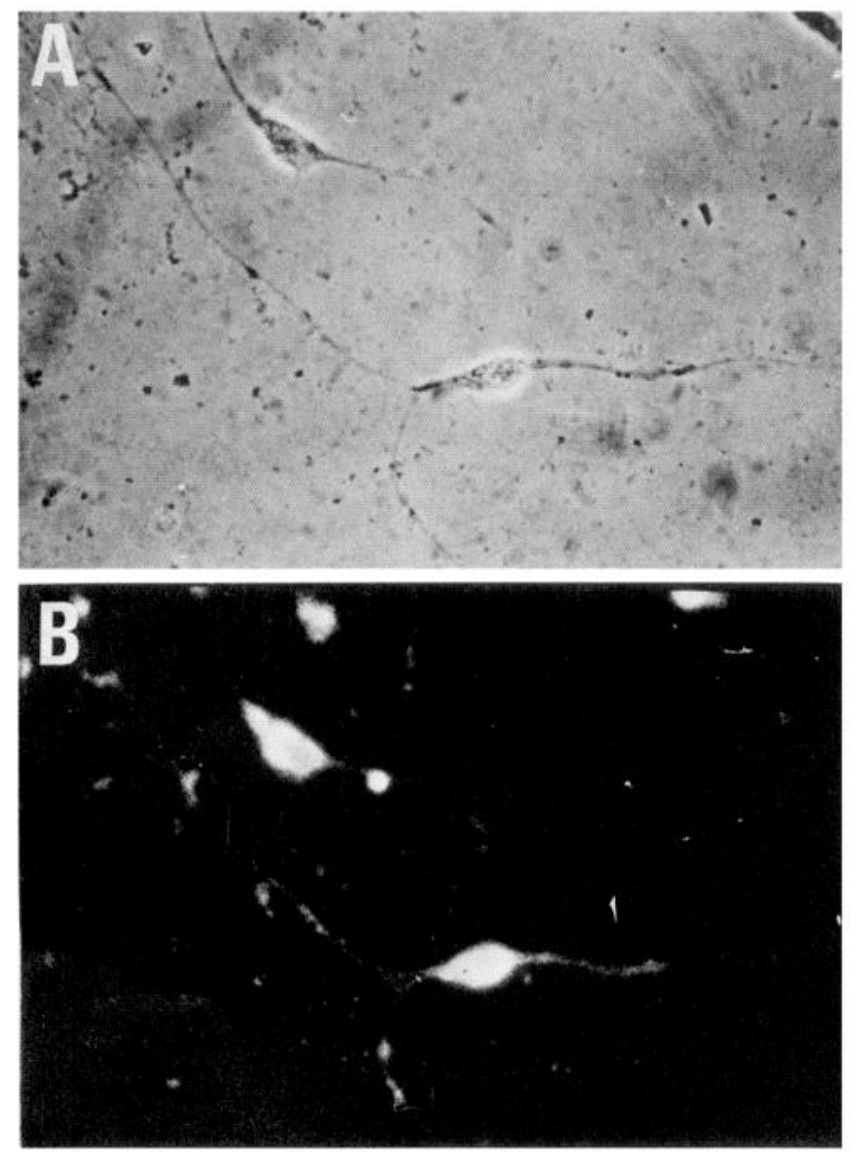

Figure 5. Schwann cells bind mOg-1. Dissociated Schwann cells $(A)$ from dorsal root ganglia were incubated with $\mathrm{mOg}-1(B)$ after $2 \mathrm{~d}$ in culture and visualized by FITC-goat anti-mouse IgM.

\section{Og-1 in the jimpy mutant mouse}

The X-linked recessive mutation, jimpy, of the mouse is characterized by the virtual absence of myelin in the CNS (Sidman et al., 1964). The biochemical nature of the defect in the jimpy is not known. Since Og-1 appears to be a marker for oligodendroglia development, its presence on cultured cells from jimpy cerebellum was examined (Table 2). Og-1 was present on cells from the jimpy cerebellum, although $\mathrm{mOg}-1$-positive cells represented a smaller percentage ( 3.5 vs $5.0 \%$ ) of the total cell population than in cultures of normal littermates. A similar proportion of these $\mathrm{Og}-1$-positive cells was also positive for mGal-C binding; however, the jimpy cells failed to bind myelin basic protein antibody even after $14 \mathrm{~d}$ of culture. A previous study (Bologa-Sandru et al., 1982) also found an absence of myelin basic protein in $14 \mathrm{~d}$ cultures of jimpy. Thus, Og-1 appears to be a marker for early development of oligodendroglia and is expressed prior to the genetic block in the jimpy mouse.

\section{Discussion}

In this report, we describe a monoclonal antibody (mOg-1) that is directed against a surface component expressed on oligodendroglial cells and Schwann cells. These cells are responsible for myelination in the CNS and PNS, respectively. Double-labeling experiments with known neural cell markers were used for this identification. Only the known oligodendroglial cell markers, GalC, rG3PDH, and MBP were seen on the Og-1-positive population. Tetanus toxin, a neuronal marker, and anti-GFAP, an astrocyte marker, labeled other cells in the population.

We could not identify all Og-1-positive cells as oligodendro-
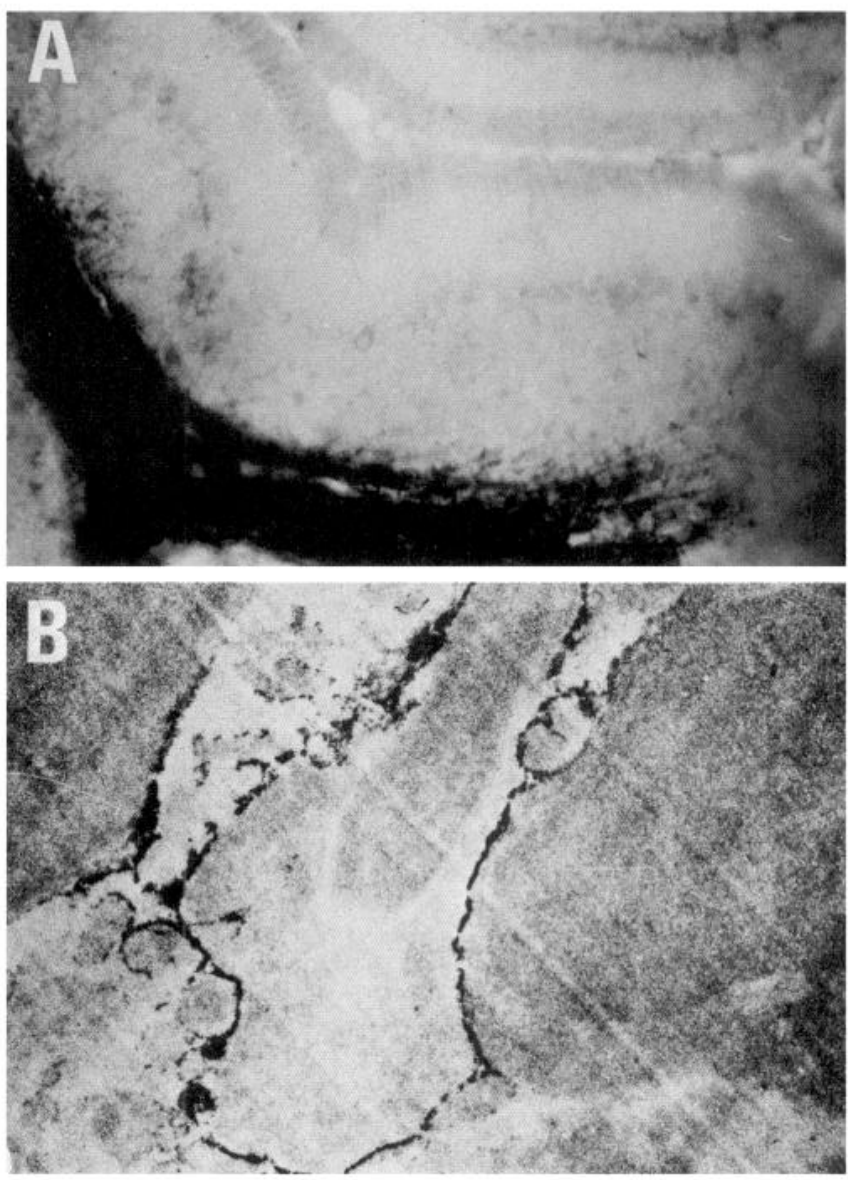

Figure 6. Labeling of cerebellar sections by mOg-1. A sagittal section of $8 \mathrm{~d}$ mouse cerebellum $(A)$ shows heavy binding of $\mathrm{mOg}-1$ to future white matter tracts as visualized by the peroxidase reaction product. Electron-microscopic localization of this labeling in $8 \mathrm{~d}$ cerebellum shows a presumptive oligodendrocyte $(B)$.

cytes since only $60-70 \%$ of them double-labeled with other oligodendroglial markers in culture. However, several lines of evidence suggest that the Og-1-positive cells that are negative for other markers may be less mature oligodendrocytes. Simple monitoring of the cultures with or without complement-mediated lysis of $\mathrm{Og}-1$-positive cells initially present indicates that the $\mathrm{Og}-1$ antigen itself is acquired with increasing time in culture.

Tissue sections, labeled with $\mathrm{mOg}-1$ and observed by light and electron microscopy, support the conclusion that Og-1-positive cells are oligodendrocytes. Positively stained cells are located deep in the granular layer and in the white matter, where we would expect to see oligodendroglial cells. However, many cells identifiable as oligodendrocytes in adult tissue by morphological criteria are not labeled. Neither are several examples of mature myelin. This may be due to incomplete penetration of the antibodies into the tissue, but positive oligodendrocytes directly adjacent to negative ones are difficult to explain on this basis. It seems more likely that $\mathrm{Og}-1$ is a cell-surface component of less mature oligodendrocytes perhaps involved in the earliest stages of myelination.

The time of appearance of Og-1 antigen in the developing mouse brain is also consistent with this interpretation. Og-1positive cells were first seen in tissue from $19 \mathrm{~d}$ fetal mice. This is $2-3 \mathrm{~d}$ before the production of GalC (Schachner and Willinger, 1979) and well before the onset of myelination. Abney et al. (1981) have shown that oligodendrocytes develop on the same schedule in dissociated cell cultures of embryonic rat brain as 

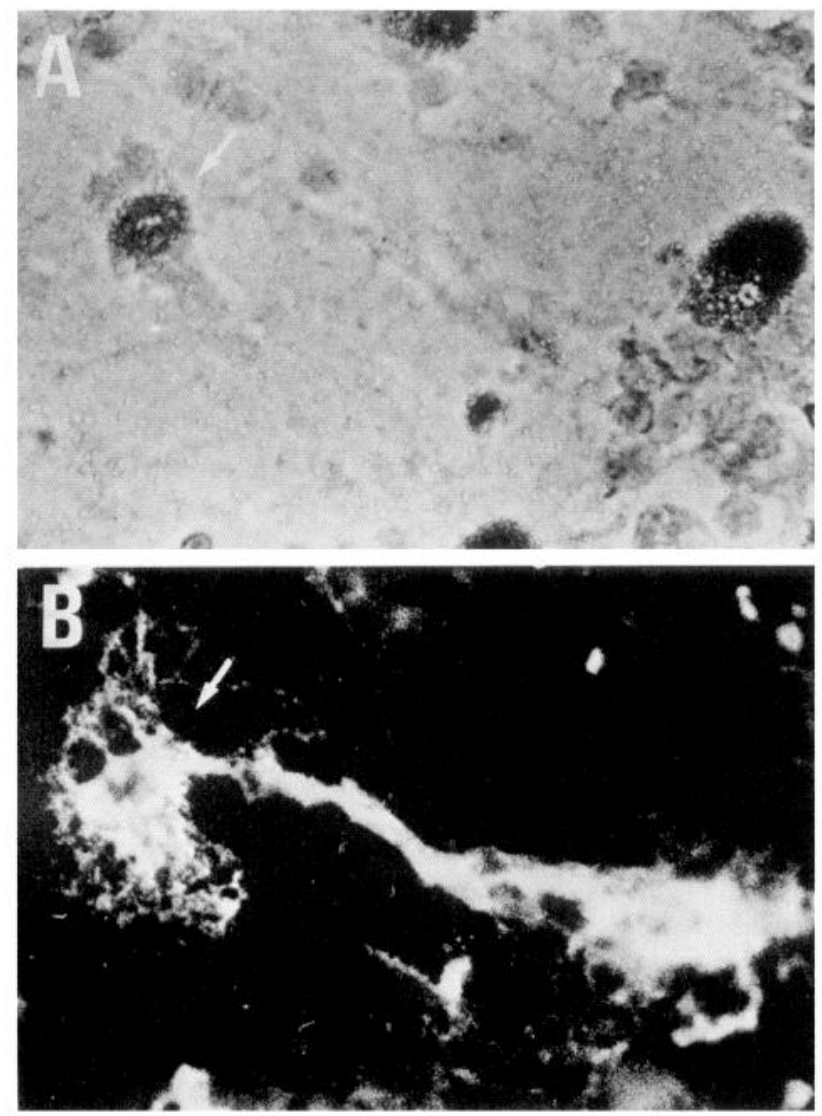

Figure 7. ${ }^{3} \mathrm{H}$-thymidine incorporation by $\mathrm{Og}$-1-positive cells. ${ }^{3} \mathrm{H}$-thymidine was added to dissociated mouse cerebellar cell cultures on day 1 , and after $3 \mathrm{~d}$ the isotope was removed and cells were incubated with mOg- 1 and FITC-GAM as described in Materials and Methods. The Og-1-positive cell (arrow) had incorporated ${ }^{3} \mathrm{H}$-thymidine $(A)$ during the in vitro culture period.

they do in vivo using GalC as a marker. Similarly, our experiments suggest the same phenomenon for Og-1. However, one must be careful in the interpretation of these results. Recent elegant studies by Raff et al. (1983) have shown that, in glial cell cultures derived from optic nerve, glial differentiation and expression of certain cell markers are influenced by the composition of the tissue culture medium. The effect of serum-free medium on cerebellar cells appears to be a precocious appearance of $\mathrm{Og}-1$, with an overall reduction in total oligodendrocyte (Og-1-positive cells) numbers after 8 to $11 \mathrm{~d}$ compared to serumcontaining cultures. This finding probably reflects a need for further cell division of the oligodendrocyte stem cells during culture, which is inhibited by $\mathrm{N} 2$ medium. In addition, experiments by others have shown that oligodendroglial differentia-

Table 1. Immunolabeling of $\mathrm{Og}-1$-positive cells with anti-GalC, antiG3PDH, or anti-MBP

\begin{tabular}{llll}
$\begin{array}{l}\text { Days in } \\
\text { culture }\end{array}$ & $\begin{array}{l}\text { GalC/Og-1 } \\
(\%)\end{array}$ & $\begin{array}{l}\text { G3PDH/Og-1 } \\
(\%)\end{array}$ & $\begin{array}{l}\text { MBP/Og-1 } \\
(\%)\end{array}$ \\
\hline 4 & 54 & 100 & 27 \\
7 & 67 & 100 & 46 \\
14 & 69 & 100 & 65
\end{tabular}

Cerebellar cultures were prepared from $6 \mathrm{~d}$ postnatal C57Bl/6 mice and doublelabeled after various times in culture. The percentage of $\mathrm{Og}-1$-positive cells expressing known oligodendroglial markers is shown.

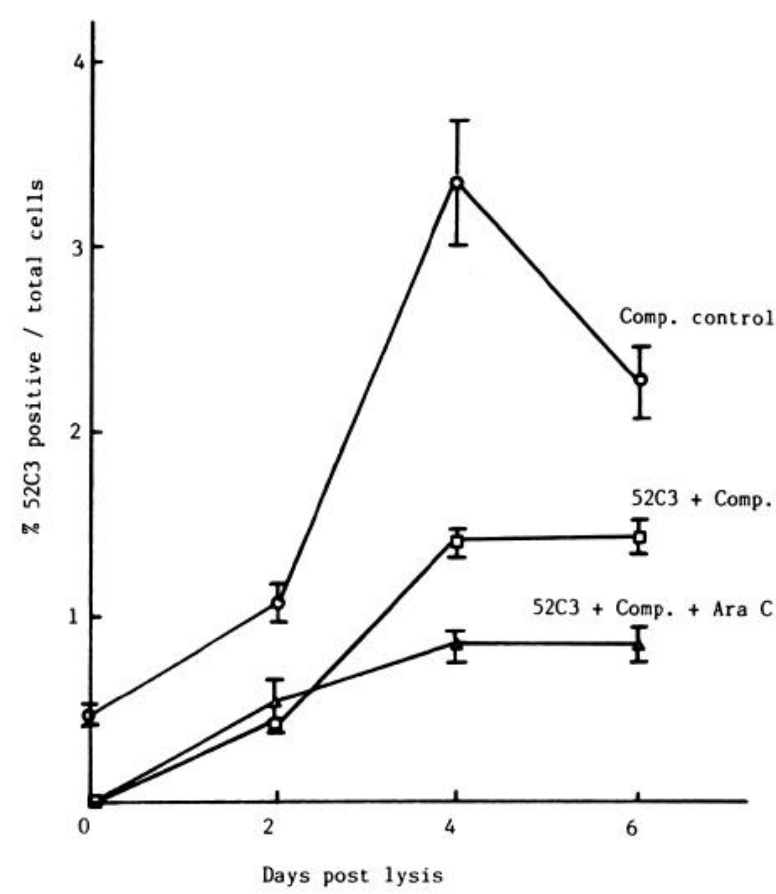

Figure 8. Acquisition of Og-1 during culture. Dissociated cerebellar cells were treated with $\mathrm{mOg}-1$ followed by guinea pig complement to lyse all the Og-1-positive cells in the culture, as described in Materials and Methods. The cultures were maintained in BEM with fetal calf serum in the presence $(\triangle)$ or absence $(\square)$ of $10^{-5} \mathrm{M}$ cytosine arabinoside (Ara-C). The acquisition of Og-1-positive cells is compared to the nontreated control $(\mathrm{O})$.

tion in vitro may be modified by the number of neurons in the culture (Barbarese et al., 1981; Bologa et al., 1982; Mirsky et al., 1980). Although we never see $100 \%$ of the Og-1-positive cells labeled with other oligodendrocyte markers, this may reflect the fact that we are making a static analysis of a dynamic population. That is, precursor cells may be constantly dividing in culture, acquiring the early marker Og-1 and then developing further. At any point in time some cells would be only partway along this path.

Oligodendroglia and Schwann cells share a number of myelinspecific proteins and glycolipids, including GalC, sulfatide, and MBP (Mirsky et al., 1980). Schwann cells stop making these markers a few days after being placed in culture, while oligodendrocytes continue for extended periods. Expression of $\mathrm{Og}-1$ antigen follows similar patterns. It is present on both Schwann cells and oligodendroglia but is lost from the surface of Schwann cells after $4 \mathrm{~d}$ in culture.

The fact that a large degree of variation in cellular shapes and morphological features exists within the oligodendroglia is commonly known, and we have observed this in the Og-1-positive population. Mori and Leblond (1970) were among the first to

Table 2. Oligodendroglial development in jimpy cultures

\begin{tabular}{llll} 
Animal & $\begin{array}{l}\text { Og-1 } \\
(\%)\end{array}$ & $\begin{array}{l}\text { GalC/Og-1 } \\
(\%)\end{array}$ & $\begin{array}{l}\text { MBP/Og-1 } \\
(\%)\end{array}$ \\
\hline Jimpy & 3.5 & 58 & 0 \\
Normal littermates & 5 & 61 & 57
\end{tabular}

Cerebellar cultures were prepared from $6 \mathrm{~d}$ postnatal mice and double-labeled after $7 \mathrm{~d}$ in culture. The percentage of $\mathrm{Og}-1$-positive $(+)$ cells in the cultures is indicated, as well as the percentage showing both labels. 


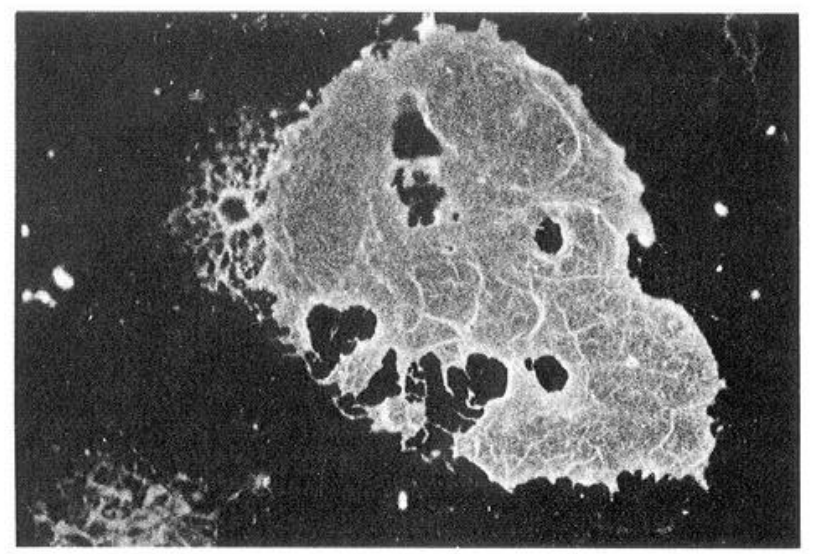

Figure 9. Lamellar sheet formation by oligodendrocytes. Large lamellar extensions millimeters in length are visualized by $\mathrm{mOg}-1$ binding and FITC-goat anti-mouse Ig in cerebellar cell cultures after $7 \mathrm{~d}$ in culture.

suggest this variation may depend on the degree of oligodendroglial maturation. Applying the structural guidelines of Skoff et al. (1976) and Privat (1975), it is apparent that many Og-1positive cells are immature oligodendroglial cells. Both oligodendroblasts and many $\mathrm{Og}$-1-positive cells have relatively large amounts of cytoplasm, which is not typical of fully differentiated oligodendrocytes.

Schachner et al. (1981) have described 4 oligodendroglialspecific antigens (O1-O4) detected by monoclonal antibodies. Cells expressing $\mathrm{O} 1$ and $\mathrm{O} 2$ antigen also express $\mathrm{GalC}$. However, only a fraction of the O3- and O4-positive cells (64 and 47\%, respectively) are GalC-positive. The O3- or O4-positive, GalCnegative cells express no other cell-type-specific markers, paralleling the situation we have observed with Og-1. Berg and Schachner (1981) further investigated the possibility that these cells were immature oligodendroglia by performing immunoelectron microscopy on monolayer cultures of fetal and early postnatal mouse cerebellum. They concluded that approximately $5 \%$ of the O-positive cells were fully mature oligodendroglia, while greater than $90 \%$ should be more appropriately labeled oligodendroblasts. Under their culture conditions, these putative oligodendroglial precursors never fully mature.

Our data suggest a similar phenomenon. Og-1 antibody labels oligodendroglia as well as immature oligodendroblasts. Only a fraction of these cells can be shown to mature in culture. However, both $\mathrm{O} 3$ and $\mathrm{O} 4$ are present at earlier developmental times than Og-1 (day 16 fetal vs day 19). In addition, O3 antibody internally labels astrocytes, and this is not seen with $\mathrm{Og}-1$. These factors suggest that Og-1 antigen is probably not identical to either $\mathrm{O} 3$ or $\mathrm{O} 4$, but these markers may be present on related cell populations. Since both $\mathrm{O} 4$ and $\mathrm{Og}-1$ are mouse IgMs, it is not possible to perform double labeling with these molecules or with the interesting monoclonal A2B5 (Eisenbarth et al., 1979); sequential binding of these antibodies and their fluorescent conjugates has not been satisfactory. Attempts to conjugate biotin directly to $\mathrm{mOg}-1$ have led to inactivation, presumably due to an active amino group in the recognition site.

Cerebellar cultures were occasionally fixed with methanol or chloroform: methanol $(1: 1)$ before the addition of antibodies directed against intracellular antigens during the double-labeling studies. If $\mathrm{mOg}-1$ was not bound and fixed with paraformaldehyde prior to this treatment, the binding pattern was lost or greatly diminished. This suggests that the organic fixation step was destroying antigenicity either through denaturation or possibly extraction of the antigen. Fixation with paraformaldehyde before binding had minimal effect.
A number of well-characterized surface components-including $\mathrm{GalC}$ and sulfatide, as well as related molecules such as glucocerebroside and ceramide-were tested for their ability to bind mOg-1. In the first method, direct binding was measured as described by Ranscht et al. (1982). The second method involved adsorption of mOg-1-containing supernatants diluted slightly less than the titer end point, by the various lipids being tested. The adsorbed antibody was then tested in the usual immunofluorescent assay system with cerebellar cultures, and, in one instance, quantitated with ${ }^{125} \mathrm{I}$-anti-mouse immunoglobulin as second antibody. Both techniques confirmed that Og-1 antigen is not GalC, sulfatide, or the related compounds. Additional studies showed that Og-1 was trypsin sensitive.

Although the Og-1 antigen is extractable from cell membranes in nonionic detergents, Og-1 is irreversibly denatured by SDS, thus precluding its identification by immunoblotting techniques. However, using ${ }^{35} \mathrm{~S}$ to metabolically label cerebellar cell cultures, a labeled molecule of approximately $90,000 M_{\mathrm{r}}$ that binds to $\mathrm{mOg}-1$ has been isolated on affinity columns containing purified goat anti-mouse IgM immunoglobulin, and it appears to be the Og-1 antigen. Although the molecular weight is similar to that of myelin-associated glycoprotein (MAG) (Quarles et al., 1983), mOg-1 does not react with rat or human MAG (A. Noronha, R. H. Quarles, and N. W. Seeds, unpublished observations).

These studies have described a cell-surface antigen, Og-1, that appears early in oligodendrocyte development. Current studies are investigating the possible role of Og-1 in oligodendrocyteaxon recognition events and myelination in reaggregate (Seeds, 1971; Seeds and Haffke, 1978) brain cell cultures.

\section{References}

Abney, E. R., P. P. Bartlett, and M. C. Raff (1981) Astrocytes, ependymal cells, and oligodendrocytes develop on schedule in dissociated cell cultures of embryonic rat brain. Dev. Biol. 83: 301-310.

Barbarese, E., and S. E. Pfeiffer (1981) Developmental regulation of myelin basic protein in dispersed cultures. Proc. Natl. Acad. Sci. USA 78: 1953-1957.

Benda, P., J. Lightbody, G. Sato, L. Levine, and W. Sweet (1968) Differentiated rat glial cell strain in tissue culture. Science 161:370371.

Berg, G., and M. Schachner (1981) Immunoelectronmicroscopic identification of $\mathrm{O}$ antigen bearing oligodendroglial cells in vitro. Cell Tissue Res. 219: 313-325.

Bologa, L., J. C. Bisconte, R. Joubert, P. J. Marangos, C. Derbin, F. Rioux, and N. Heischkowitz (1982) Accelerated differentiation of oligodendrocytes in neuron-rich embryonic mouse brain cell cultures. Brain Res. 252: 129-136.

Bologa-Sandru, L., H. P. Siegrist, A. Z'graggen, K. Hofmann, U. Weismann, D. Dahl, and N. Herschkowitz (1981) Expression of antigenic markers during the development of oligodendrocytes in mouse brain cultures. Brain Res. 210: 217-229.

Bologa-Sandru, L., H. P. Siegrist, A. Z'graggen, U. Weismann, and N. Herschkowitz (1982) Abnormal oligodendrocyte differentiation in a mouse mutant with a defect in myelination. In Inborn Errors of Metabolism in Humans, F. Cockburn and R. Gitzelmann, eds., pp. 201-208, Alan Liss, New York.

Bottenstein, J. E., and G. H. Sato (1979) Growth of a rat neuroblastoma cell line in serum-free supplemental medium. Proc. Natl. Acad. Sci. USA 76: 514-517.

Dahl, D., and A. Bignami (1973) Immunochemical and immunofluorescence studies of the glial fibrillary acidic protein in vertebrates. Brain Res. 61: 279-293.

Eisenbarth, G. S., F. Walsh, and M. Nirenberg (1979) Monoclonal antibody to a plasma membrane antigen of neurons. Proc. Natl. Acad. Sci. USA 76: 4913-4917.

Fields, K., C. Gosling, M. Megson, and P. Stern (1975) New cell surface antigens in rat defined by tumors of the nervous system. Proc. Natl. Acad. Sci. USA 72: 1296-1300.

Galfre, G., S. C. Howe, C. Milstein, G. W. Butcher, and J. C. Howard (1977) Antibodies to major histocompatibility antigens produced by hybrid cell lines. Nature 266: 550-552. 
Joffe, S., and M. M. Rapport (1963) Identification of an organ specific lipid hapten in brain. Nature 197: 60-62.

Kennedy, P. G. E., R. P. Lisak, and M. C. Raff (1980) Cell typespecific markers for human glial and neuronal cells in cultures. Lab. Invest. 43: 342-351.

Kohler, G., and C. Milstein (1976) Derivation of specific antibodyproducing tissue culture and tumor lines by cell fusion. Eur. J. Immunol. 6: 511-519.

Kohler, G., S. C. Howe, and C. Milstein (1976) Fusion between immunoglobulin-secreting and nonsecreting myeloma cell lines. Eur. J. Immunol. 6: 292-295.

Krystosek, A., and N. W. Seeds (1981) Plasminogen activator secretion by granule neurons in cultures of developing cerebellum. Proc. Natl. Acad. Sci. USA 78: 7810-7814.

Leveille, P. J., J. F. McGinnis, D. S. Maxwell, and J. DeVellis (1980) Immunocytochemical localization of glycerol-3-phosphate dehydrogenase in rat oligodendrocytes. Brain Res. 196: 287-305.

Lisak, R. P., D. E. Pleasure, D. H. Silberberg, M. C. Manning, and T. Saida (1981) Long-term culture of bovine oligodendroglia isolated with a percoll gradient. Brain Res. 223: 107-122.

Lowry, O. H., N. Rosebrough, A. Farr, and R. Randall (1951) Protcin measurement with the folin phenol reagent. J. Biol. Chem. 193: 265275.

McCarthy, K. D., and J. DeVellis (1980) Preparation of separate astroglial and oligodendroglial cultures from rat cerebral tissue. J. Cell Biol. 85: 890-892.

Mirsky, R., J. Winter, E. R. Abney, R. M. Pruss, J. Gavrilovic, and M. C. Raff (1980) Myelin-specific proteins and glycolipids in rat Schwann cells and oligodendrocytes in culture. J. Cell Biol. 84: 483-494.

Mori, S., and C. D. Leblond (1970) Electron microscope identification of three classes of oligodendrocytes and a preliminary study of their proliferative activity in the corpus collosum of young rats. J. Comp. Neurol. 139: 1-30.

Norton, W. T., and L. A. Autilio (1966) The lipid composition of purified bovine brain myelin. J. Neurochem. 13: 213-222.

Oi, V. T., and L. A. Herzenberg (1980) Immunoglobulin-producing hybrid cell lines. In Selected Methods in Cellular Immunology, B. Mishell and S. Shiigi, eds., pp. 351-372, Freeman, San Francisco, CA.

Privat, A. (1975) Postnatal glioagenesis in the mammalian brain. Int. Rev. Cytol. 40: 281-323.

Quarles, R. H., G. Barbarash, D. Figlewicz, and L. McIntyre (1983) Purification and partial characterization of the myelin associated glycoproteins from adult rat brain. Biochim. Biophys. Acta 75: 140143.

Raff, M. C., R. Mirsky, K. L. Fields, R. P. Lisak, S. H. Dorfman, D. H. Silberberg, N. A. Gregson, S. Leibowitz, and M. C. Kennedy (1978) Galactocerebroside is a specific cell-surface antigenic marker for oligodendrocytes in cultures. Nature 274: 813-816.

Raff, M. C., R. H. Miller, and M. Noble (1983) A glial progenitor cell that develops in vitro into an astrocyte or an oligodendrocyte depending on culture medium. Nature 303: 390-396.

Ranscht, G., P. A. Clapshaw, J. Price, M. Noble, and W. Seifert (1982) Development of oligodendrocytes and Schwann cells studied with a monoclonal antibody against galactocerebroside. Proc. Natl. Acad. Sci. USA 79: 2709-2713.

Ransom, B. R., E. Neale, M. Henkart, P. N. Bullock, and P. G. Nelson (1977) Mouse spinal cord in cell culture. I. Morphology and intrinsic neuronal electrophysiological properties. Neurophysiology 40:11321150.

Schachner, M., and M. Willinger (1979) Developmental expression of oligodendrocyte-specific cell surface markers: Nervous system antigen (NS-1), cerebroside, and basic protein of myelin. In The Menarini Series of Immunopathology, Vol. 2, pp. 37-60, Schwabe, Basel.

Schachner, M., S. K. Kim, and R. Zehnle (1981) Developmental expression in central and peripheral nervous system of oligodendrocyte cell surface antigens ( $O$ antigens) recognized by monoclonal antibodies. Dev. Biol. 83: 328-338.

Seeds, N. W. (1971) Biochemical differentiation in reaggregating brain cell culture. Proc. Natl. Acad. Sci. USA 68: 1858-1861.

Seeds, N. W. (1975) Cerebellar cell surface antigen of mouse brain. Proc. Natl. Acad. Sci. USA 72: 4110-4114.

Seeds, N. W., and J. M. Collins (1983) Oligodendroglial differentiation in cerebellar cell cultures as monitored with a monoclonal antibody. Fed. Proc. 42: 2025 (abstr.).

Seeds, N. W., and S. C. Haffke (1978) Ultrastructure of developing mouse brain cell reaggregates. Dev. Neurosci. 1: 69-79.

Seeds, N. W., and M. J. Marks (1979) Sulfatide synthesis by neural cell lines. Dev. Neurosci. 2: 249-253.

Sidman, R. L., M. Dickie, and S. Appel (1964) Mutant mice (quaking and jimpy) with deficient myelination in the CNS. Science 144:309310.

Skoff, R. P., D. L. Price, and A. Stocks (1976) Electron microscopic autoradiographic studies of gliogenesis in rat optic nerve. II. Time of origin. J. Comp. Neurol. 169: 313-334.

Sommer, I., and M. Schachner (1981) Monoclonal antibodies (O1 to O4) to oligodendrocyte cell surfaces: An immunocytological study in the central nervous system. Dev. Biol. 83: 311-327.

Sternberger, N. H., Y. Itoyama, M. W. Kies, and H. deF. Webster (1978) Myelin basic protein demonstrated immunochemically in oligodendroglia prior to myelin sheath formation. Proc. Natl. Acad. Sci. USA 75: 2521-2524.

Stuhlfauth, I., and N. W. Seeds (1983) Cerebellar plasma membrane proteins and their antisera. Dev. Biol. 98: 80-100.

Szuchet, S., and K. Stefansson (1980) In vitro behavior of isolated oligodendrocytes. Adv. Neurobiol. 1: 313-316.

Tennekoon, G. I., Y. Kishimoto, I. Singh, G. Nonaka, and J. Brousse (1980) The differentiation of oligodendrocytes in the rat optic nerve. Dev. Biol. 79: 149-158.

Yavin, A., and E. Yavin (1977) Synaptogenesis and myelinogenesis in dissociated cerebral cells from rat embryo on polylysine coated surfaces. Exp. Brain Res. 29: 137-147.

Yavin, E., A. Yavin, W. H. Habig, M. C. Hardegree, and L. D. Kohn (1981) Tetanus toxin association with developing neuronal cell cultures. J. Biol. Chem. 256: 7014-7022.

Zimmerman, H., and N. Maier (1948) Experimental brain tumors. Proc. NY Pathol. Soc., pp. 40-42. 